\title{
Intelligent Technology Support Chinese High-End Equipment Manufacturing Upgrades and Development
}

\author{
Yong Tao
}

\begin{abstract}
Intelligent, networking and green technologies are the main directions in which China races to a commanding height of advanced manufacturing. The promoting the transformation, upgrading and innovation of advanced industry through intelligent manufacturing has a major typical guiding and demonstration effect on the development of Chinese high-end equipment manufacturing industry. This paper analyzes the development trend of intelligent manufacturing, illustrates the urgent demand of the transformation, upgrading and innovation of Chinese advanced industry for intelligent manufacturing, sets forth an idea and goal for the development of intelligent manufacturing in the aviation field, lists relevant development priorities, and puts forward relative suggestions.
\end{abstract}

Index Terms-Intelligent manufacturing, high-end equipment, Upgrading and Innovation, development strategy.

\section{INTRODUCTION}

Intelligent manufacturing is not only a main direction in which China races to a commanding height of advanced manufacturing, but also a propeller for the upgrading of manufacturing industry [1]-[3]. Aviation industry is a typical capital-intensive, tech-intensive and collaboration-intensive industry, and a typical representative of high-end equipment manufacturing industry, characterized by high monopolization and high technology. All major countries in the world treat aviation industry as a national strategic industry and an embodiment of a country's overall national strength since it is not only an important basis for a country's national defense safety, but also a reflection of a country's industrial development. Aviation industry is an important industry that can drive the growth of national economy; the development and production of advanced aviation products will certainly boost the development of highly-sophisticated technologies. The aviation industry is a propeller for industrial transformation and upgrading.

Taking Boeing Company for example, the key reason why it can always hold the lead in the world is due to its digital intelligent aviation manufacturing. It adopts a global cooperative development mode, pays high attention to overall design, and outsources detailed design to its partners in the world. Meanwhile, it evolves towards knowledge-based innovative design, intelligent equipment-centric digital production platform and global cooperative intelligent

Manuscript received February 29, 2016; revised June 8, 2016.

Yong Tao is with the National Laboratory on Aerospace/The Chinese Institute of Aeronautical Engineering Development Strategies, Beihang University, Beijing, CO 100191 China (e-mail: taoy@buaa.edu.cn). manufacturing [4], [5].

At the technical level, the intellectualization of manufacturing industry is a development direction of the global manufacturing industry. At the environmental level, the manufacturing industry needs to achieve green development. At the level of industrial structure, the manufacturing industry is morphing into a service industry. It is urgently necessary to speed up the development of intelligent manufacturing equipment and products, organize the research and development of high-grade numerical control machines, industrial robots, material additive manufacturing equipment and other types of smart manufacturing equipment as well as intelligent production lines that have the function of depth perception, intelligent decision and automatic execution to propel engineering and industrialization. In addition, it is also necessary to accelerate the intellectualized transformation of the production facilities in such industries as aviation, machinery and shipping, to improve the ability of precise manufacturing and agile manufacturing.

It is imperative to gain a place in the increasingly fierce international civil aviation industry competition in a relatively short time, catch up with and surpass the development and manufacture level of developed countries' aviation industry, and make use of the advanced manufacture technique, so that the aviation industry should maximize the use of late-starting advantages to step onto the road of independent innovation to realize overtaking around the corner. At the same time, the transformation, upgrading and innovation of aviation industry through intelligent manufacturing also has a major typical guiding and demonstration effect on the development of Chinese high-end equipment manufacturing industry, able to boost the transformation and upgrading of the entire high-end equipment manufacturing industry.

\section{INTELLIGENT MANUFACTURING IS AN URGENT DEMAND OF CHINESE ADVANCED INDUSTRY FOR TRANSFORMATION, UPGRADING AND INNOVATION}

\section{A. Intelligent Manufacturing Is an Iconic Technology and Commanding Height of the New Industrial Revolution}

Manufacturing industry plays a leading role in the global industrialization process. After undergoing economic globalization and IT revolution, the world has encountered lots of challenges and problems, such as resource shortage, financial crisis and economic recession. The major economies in the world have begun to explore and introduce policies one after another to resolve the difficulty.

The Obama Administration saw "manufacturing 
renaissance" and "re-industrialization" as an important way for financial problem solving. It started from high-grade, high-precision, advanced technologies, such as intelligent manufacturing, material additive manufacturing and bio-manufacturing, to initiate manufacturing mode innovation and manufacturing technology change. It will occupy the strategic commanding height of the international manufacturing industry in the 21 st century. America boost the Internet-based intelligent manufacturing and set up a national network of manufacturing innovation to ensure the local invention and manufacturing of the next generation of products. American "re-industrialization", which is based on artificial intelligence, robot and digital intelligent manufacturing, is expected to morph into a new industrial revolution [6], [7].

Germany, UK and other EU members are speeding up the development of sustainable manufacturing and intelligent manufacturing to maintain the traditional predominant position of manufacturing industry to cope with the post-crisis era [8], [9]. The EU came up with the idea of "future factory", which means to reduce cost, improve manufacturing system performance and enhance capacity impetus when product variability is being continuously improved and product yield is being constantly changed by a wide margin [10]. The "Industry 4.0" proposed by Germany in 2013 has been put on the agenda in full swing and become an arrow fitted to the string, which is initiative based on cyber physics system and themed on intelligent plant, intelligent production and intelligent logistics with industrial Internet of things and industrial Internet of services at the core [11].

A new industrial revolution has taken place. The new industrial revolution is in essence a production mode reform dominated by such emerging information technologies as artificial intelligence, Internet of things, cloud computing and big data. It is driven by such significant technology innovations and fusions as digital manufacturing and Internet. In other words, it is a major change of the traditional "mass production" into "digital manufacturing", "mass customization" and "ubiquitous manufacturing". The intelligent manufacturing, material additive manufacturing, Nano-manufacturing, bio-manufacturing and other emerging manufacturing modes as well as related industries will come into being inevitably. The social production modes will be transformed concurrently. It will eventually bring mankind into an eco-harmonious, green and low-carbon, sustainable society [12].

\section{B. Intelligent Manufacturing Is a Propeller for the Upgrading of Chinese Manufacturing Industry}

China's economy is facing serious challenges and major opportunities from the new industrial revolution. With the fast rise in the cost of essential factors and the further enhancement of resource and environmental constraints, the domestic economy has ushered in an intermediate-speed growth period. Additionally, owing to the lack of core competitiveness, the traditional low-cost competitive advantage of Chinese manufacturing industry has weakened constantly under the "double pressure" from the "re-industrialization" in the European and American developed countries and the low-cost industrial transfer to other developing countries.

In order that Chinese manufacturing industry grow bigger and stronger, the technology following strategy must be transformed into self-development strategy and into technical surmounting strategy. The traditional manufacturing must be transformed into digital, network-based, intelligent manufacturing. The extensive manufacturing must be transformed into quality-benefit manufacturing, and the contaminative manufacturing must be transformed into green manufacturing. The production-oriented manufacturing must be transformed into production-oriented + service-oriented manufacturing.

\section{Intelligent Manufacturing Promotes the Transformation, Upgrading and Innovation of Chinese High-End Equipment Manufacturing}

The aviation industry is a driving force for industrial transformation and upgrading. All major countries in the world treat aviation industry as a national strategic industry and an embodiment of a country's overall national strength since it is not only an important basis for a country's national defense safety, but also a reflection of a country's industrial development. The aviation industry is an important industry that can drive the growth of national economy, and the development and production of advanced aviation products will certainly boost the development of highly-sophisticated technologies.

The intelligent aviation equipment manufacturing will form a new industrial mode by enhancing the intelligent processing capacity of aviation equipment industry based on the adoption of modern computing and communication technology, automation technology and industrial Internet. By setting up a manufacturing system with intelligent plant and intellectual product, the existing digital design and automatic manufacturing will be constantly improved and developed. The intelligent equipment and manufacturing systems, manufacturing execution, integrated automation systems and industrial chain collaboration platforms are the key support basis for the transformation, upgrading and great-leap-forward development of aviation industry. It is featured by "dynamic perception, real-time analysis, autonomous decision-making and precise execution".

The future development goal is to realize the integration of design and manufacturing with intelligent system at the core, complete production planning and process design in the process of detailed design, complete the simulation analysis of product performance and process engineering in a virtual environment. It will ensure the one-time success rate of production after digital quantity arrives at the manufacture field, give real-time feedback on production state. It will optimize design scheme to form a fully closed-loop control process made up of "dynamic perception-realtime analysis-autonomous decision-making-precise execution".

Intelligent manufacturing can bring a guiding and demonstration effect on Chinese high-end equipment manufacturing industry. It can boost the transformation and upgrading of the entire high-end equipment manufacturing industry by promoting the transformation, upgrading and innovation of aviation industry through intelligent manufacturing. 


\section{DEVELOPMENT STRATEGY}

\section{A. Development Idea and Goal}

We take the opportunity brought by national intelligent manufacturing development to promote the implementation and demonstration of "Made in China 2025" in aviation manufacturing industry. It can improve the level of aviation manufacturing digitization, networking and intellectualization, and enhance the industry chain collaboration. We try hard to improve the independence design level and system integration capability around a batch of iconic and highly representative major aviation products and device. The technical innovations and major projects in aviation field, such as large aircraft, general aviation and aircraft engine, should be in accordance with the principle of "breakthrough at key points and quality improvement", to resolve the problem of key generic technology as well as engineering and industrialization technologies. It will speed up the engineering application of intelligent manufacturing equipment and the demonstration engineering of digital workshop/plant, manufacturing process and intelligent supply chain control, organize the pilot application of high-end numerical control machines, industrial robots, material additive manufacturing devices and other types of smart manufacturing equipment as well as intelligent production lines. It will boost the development of intelligent manufacturing, mass personalized customization, networked cooperative manufacturing and service-oriented manufacturing, to accelerate the formation of a networked industrial ecological system in the aviation manufacturing industry. It will promote the development, transformation and upgrading of high-end aviation equipment manufacturing industry.

\section{B. Develop Priorities}

1) Set up an intelligent manufacturing system and overall structure for Chinese equipment industry

The basic components, core elements, supporting environments, key technologies and processing objects of the whole value chain of aviation equipment industry should be analyzed and researched. The essential elements, correlations and environmental requirements of intelligent aviation equipment manufacturing should be summarized in accordance with National Guidelines on the Establishment of a Standard System for Intelligent Manufacturing. By reference to the domestic and foreign advanced manufacturing modes and enterprise control system integration criteria, an intelligent manufacturing system and overall structure oriented towards aviation equipment industry should be put forward.

\section{2) Resolve the critical technical problem of intelligent} equipment manufacturing

We summarize the bottleneck problems and critical technical problems of intelligent aviation equipment manufacturing, analyze the requirements for perception, analysis, decision-making and execution in product development process. We propose the development requirements and paths of the high-end numerical control machines, industrial robots, material additive manufacturing equipment and other types of smart manufacturing equipment as well as intelligent production lines. They have the function of depth perception, intelligent decision and automatic execution. They resolve the technical problem of industrial cloud-based cyber physical system(ICPS), Web-based collaborative manufacturing and digital integration of design and manufacturing, and propose an approach for the research, engineering application and industrialization development of the key technologies involved by the intelligent production lines/workshops, intelligent enterprises and enterprise alliances required for the development and production of aviation equipment.

\section{3) Put forth a development strategy and application} demonstration project of intelligent manufacturing 2025 for equipment enterprises

We summarize and generalize the core enhancement factors of independent development level and system integration capability and industrial chain collaboration capability in the development process of typical aviation equipment products. We research the foreign advanced manufacturing modes and evolution process and analyze the development trend and requirements of intelligent manufacturing in aviation equipment industry. Based on the intelligent aviation equipment manufacturing system and overall structure, we resolve the problem of key generic technology, independent industrial software development and application, intelligent manufacturing equipment and engineering technology and industrialization technology. We put forth an application demonstration project of typical intelligent manufacturing in aviation industry.

\section{KEY TASKS IN CHINESE INTELLIGENT AVIATION MANUFACTURING}

\section{A. Research and develop Key Intelligent Processing Equipment of Aviation}

\section{1) Intelligent control-based CNC machining processing} equipment of aviation

We develop the key technologies such as intelligent online monitoring of numerically controlled machining, intelligent vibration control over high-efficiency, high-precision numerically controlled machining, and intelligent $\mathrm{CNC}$ system of surface direct interpolation. It includes the quick field test and analysis of high-end numerical control machine tool servo and spindle tool system as well as the dynamic characteristics of complete machine. We improve the accurate identification and quick forecast of NC milling system state, the adaptive adjustment of machining parameters. We improve the use efficiency of numerical control machine, develop a control algorithm with the function of intelligent adaptation and self-learning function to improve the accuracy of mechanical system and enhance the system characteristics. We make use of intelligent technologies for kinematic error compensation, make the vibration control of $\mathrm{NC}$ milling efficient, intelligent and universal.

\section{2) Key equipment in intelligent aeronautical assembly robot}

We carry out a research on intelligent aeronautical drilling 
robot, intelligent spraying robot and multi-robot collaborative assembly. We break the critical technical bottlenecks of intelligent drilling robot in accordance with its defects such as big volume, high cost, low degree of automation, unstable machining accuracy and poor conformity. We carry out a research on the key technology of collaborative robot arm assembling. We focus on aeronautical robot spraying process and equipment, resolve the key technical problems of robot force control and online precision measurement. We propose the complete machine-oriented intelligent spraying robot system and spatial multidimensional track design. We present the spraying track programming and rectifying technology of complicated surface, the high-precision variable flow transport technology, and the surface coating and optimization technology of the fuselage made of multi-matrix materials, to improve the quality and efficiency of China's aviation manufacturing.

\section{3) Intelligent flexible aeronautical tooling equipment}

We tackle the problems in the key technologies of reconfigurable flexible assembly tooling for cartridge connection, intelligent flexible tooling for pipe assembling and welding, and self-adaptive stress-free assembly tooling for aircraft components. We solve the problems in the key technologies for the classification and coding, intelligent configuration design, stability analysis and laser measurement and control of the standard components in the reconfigurable assembly jig used for aeronautical cartridge connection. We form a complete set of technical regulations for the configuration design, installation and performance verification of reconfigurable flexible jig. We provide support for the intelligent flexible assembly of aviation products. We carry out a research on such key technologies as flexible pipe coupling clamper welded of multiple pipes, automatic clamper configuration and work space analysis, intelligent pipe clamper, and posture alignment based on force sensor and vision measurement data feedback. We realize the rapid process preparation and assembly welding of the different-sized complex pipe systems that extend in different directions.

\section{B. Chinese Industrial Internet-Based Aeronautical Collaborative Cloud Manufacturing}

We tackle the problems in the key technologies for aeronautical collaborative cloud manufacturing, manufacturing resource virtualization and cloud adaptive access, industrial cloud resource capability service aggregation. We research the virtualization and cloud adaptive access technologies of Web-based application systems, independent application systems and other manufacturing software resources. We develop the virtualization and cloud adaptive access technologies of CNC machining equipment, testing equipment and other manufacturing equipment resources. We present the virtualization and cloud adaptive access technologies of data knowledge resources. We develop manufacturing service intelligent matching and discovery technologies, as well as manufacturing service dynamic integration and service composition optimization technologies. We solve the problem of manufacturing task dispersion, uncertainty and multi-granularity. We develop multidisciplinary collaborative design service, process-resource matching optimization service, fast scheduling and dynamic scheduling service, test service, and supply collaboration service technologies in accordance with the high interaction and close cooperation between the enterprises affiliated to the group.

C. Chinese Intelligent Aviation Manufacturing based on the Digital Integration of Design and Manufacturing

\section{1) Full three-dimensional integrated technology for aviation design and manufacturing}

We tackle the problems in the key technologies for full three-dimensional correlative product model construction and evolution, full three-dimensional digital process design and simulation. We integrate application of lightweight threedimensional information model in manufacturing shops, and put three-dimensional design information, three- dimensional manufacturing information, three-dimensional tooling information and three-dimensional metrical information in a three-dimensional mathematical model using MBD technology. We fully define the three-dimensional product information that supports full life circle, and build a unified data model that supports product application in full life circle. We develop a model-driven knowledge-based aviation process design technology, establish a systemic method for product manufacturing process design and decision analysis. We study the establishment of a process digital prototype for a machining simulation and process flow analysis of the aeronautical fixed intelligent manufacturing equipment.

\section{2) Lifecycle management-based intelligent aviation manufacturing}

We tackle the problems in the key technologies for product lifecycle information modeling and management, model-based product lifecycle management and integration of design and manufacturing. We develop a process and data integration and management technology for complex aeronautical product lifecycle, as well as a digital product and process modeling technology for knowledge-intensive development. We research MBD standard and its application in complex aeronautical product development. We develop an establishment method of product lifecycle management system for model-based digital product definition, change, transfer and application. We develop an integrated design and manufacturing technology that can realize information recalling for the effective sharing and transfer of complex aviation product and process information at each stage of the full life cycle. We build a an integrated design and manufacturing platform to form a sustainable development mechanism in which product model data and process management data are integrated together between multi-application systems.

\section{CONCLUSIONS}

This paper analyzed the international developing trend of intelligent manufacturing. It summarized the urgency and inexorable trend of developing intelligent aviation manufacturing, which regards intelligent manufacturing as an iconic technology of the new industrial revolution and deep integration of informationization with industrialization. It is a 
core development goal from a perspective of the transformation, upgrading and innovation of aviation industry. The paper put forward an idea, target and emphasis for the development of intelligent aviation manufacturing, and then elaborated on the key tasks in intelligent aviation manufacturing.

\section{ACKNOWLEDGEMENTS}

Thank you for the support of strategic consulting research project of Chinese Academy of Engineering.

\section{REFERENCES}

[1] The Xinhua News Agency, "The State Council issued the '2025 Chinese manufacturing'," China Paper Newsletter, vol. 5, p. 5, 2015.

[2] Y. L. Xu, "From the 'two integration' to 'Chinese manufacturing 2025, , Shanghai Informatization, vol. 1, pp. 24-27, 2015.

[3] J. J. Ning, "Internet+' plan of action for the implementation of the background, connotation and main content," e-Government, vol. 6 , 2015.

[4] Y. Yu, J. Tao, and Y. Q. Fan, "The Boeing 787 aircraft assembly technology and process," Aeronautical Manufacturing Technology, vol. 14, pp. 44-47, 2009.

[5] C. Wang, "Quality management for airliner collaborative design and manu-facturing," Ph.D. dissertation, Shanghai University, Shanghai, 2013.

[6] Z. R. Liao, "The United States re-industrialization and its influence," International Study Reference, 2013.

[7] Y. W. Liu, "The United States manufacturing innovation network power intelligent manufacturing," International Aviation, vol. 6, pp. 70-72, 2015

[8] F. J. Wang, "United States, Japan, Germany and three equipment manufacturing reflux after the financial crisis impact on China," Review of Economic Research, vol. 63, pp. 7-13, 2012.

[9] W. Tong, "Development strategy of advanced manufacturing in Britain at post-financial-crisis," Quanqiu Keji Jingji Liaowang, vol. 26, pp. 10, 2011.
[10] R. S. Liu, "The roadmap factory of the EU future factory," Scientific Chinese, vol. 1, pp. 25-27, 2015.

[11] X. W. Wang, "The future of intelligent manufacturing industry from the German industrial 4.0 strategy," Chinese Information, vol. 15, pp. 8-9, 2014.

[12] J. C. Liu and G. Li, "The way of Chinese manufacturing to deal with information technology challenges and opportunities," Review of Economic Research, vol. 33, pp. 13-20, 2014.

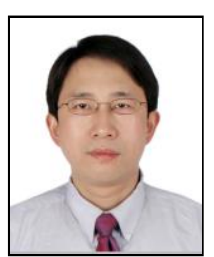

Yong Tao was born in 1979-8-22. He received the B.S degree and M.S. degree from the Chongqing University, Chongqing, China, in 2002 and 2005, respectively. He received the Ph.D. degree in mechanical and electronic engineering from Beihang University, Beijing, China, in 2005 , focusing on service robot and application.

$\mathrm{He}$ is a lecture of National Laboratory on Aerospace, the Chinese Institute of Aeronautical Engineering Development Strategies, Beihang University. His main research areas include the development strategy consulting, laboratory monitoring and management, intelligent manufacturing, aircraft flexible assembly manufacturing technology, industrial robot integration and application. In the research of advanced control technology and integrated application of industrial robot, the palletizing robot and the flexible rail drilling robot is developed. Now he is the technical person in charge of 863 key projects of digital design platform for industrial robots, the natural foundation of the young fund with the characteristics of the body of the variable stiffness of the mechanical arm. He has participated in a number of national 863 and support program project, natural funding projects. 